\title{
Effect of dentin contamination with two hemostatic agents on bond strength of resin-modified glass ionomer cement with different conditioning
}

\author{
Amr SAAD ${ }^{1,2}$, Go INOUE ${ }^{1}$, Toru NIKAIDO ${ }^{1}$, Ahmed M. A ABDOU ${ }^{1,3}$, Mahmoud SAYED ${ }^{1}$, Michael F. BURROW \\ and Junji TAGAMI ${ }^{1}$ \\ ${ }^{1}$ Cariology and Operative Dentistry, Division of Oral Health Sciences, Graduate school of Medical and Dental Sciences, Tokyo Medical and Dental \\ University, 1-5-45 Yushima, Bunkyo-ku, Tokyo 113-8549, Japan \\ ${ }^{2}$ Faculty of dentistry, Cairo University, 1-Al Saraya St., Manial, Cairo, Egypt \\ ${ }^{3}$ Modern University for technology and Information, El-hadaba El-Wosta, Mokatam, 5th district, Cairo, Egypt \\ ${ }^{4}$ Faculty of Dentistry, The University of Hong Kong, Prince Philip Dental Hospital, 34 Hospital Rd, Sai Ying Pun, Hong Kong SAR, China \\ Corresponding author, Go INOUE; E-mail: inoue.ope@tmd.ac.jp
}

\begin{abstract}
This study evaluated the effect of two hemostatic agents on bond strength of resin-modified glass ionomer cement (RMGIC) to root dentin after using different pretreatment solutions compared to resin composite with a 2-step self-etch adhesive. Dentin specimens were either uncontaminated or contaminated with a ferric sulphate or aluminum chloride astringent, RMGIC was applied after conditioning with; Cavity Conditioner, Self Conditioner or Clearfil SE Primer, while a resin composite was bonded using Clearfil SE Bond. Microtensile bond strength ( $\mu$ TBS) values and failure modes were determined. Two-way ANOVA revealed that hemostatic agents did not significantly affect the RMGIC bond strength with any conditioning material $(p>0.05)$. SE Primer pretreatment provided the highest $\mu$ TBS values among RMGIC groups. For the resin composite, ferric sulphate astringent significantly reduced $\mu$ TBS value $(p \leq 0.001)$. Scanning electron micrographs of representative dentin surfaces contaminated with the hemostatic agents showed effects on smear layer removal and dentinal tubule occlusion.
\end{abstract}

Keywords: Hemostatic agents, Bond strength, Resin-modified glass ionomer cement, Dentin conditioning, Resin composite

\section{INTRODUCTION}

One of the clinical challenges that dentists face during restorative procedures, especially in the cervical area, is blood and gingival crevicular fluid contamination which may affect the quality of the bond between a restoration and tooth structure ${ }^{1,2}$. Therefore, where possible, rubber dam placement is used to achieve optimal isolation, however, in some clinical situations rubber dam placement is not possible ${ }^{3)}$.

Topical hemostatic agents have been developed and used as a method to achieve hemostasis before placement of a restoration. Among these hemostatic agents; aluminum chloride $\left(\mathrm{AlCl}_{3}\right)$ used at a concentration between $0-25 \%$ which achieves hemostasis by protein precipitation and constriction of blood vessels ${ }^{4}$, and $20 \%$ ferric sulfate $\left(\mathrm{Fe}_{2}\left(\mathrm{SO}_{4}\right)_{3}\right)$ solutions which achieve hemostasis via chemical reaction of both the ferric and sulfate ions to agglutinate blood proteins and form plugs to occlude the capillary orifices ${ }^{5}$. Because clinicians may use hemostatic agents by soaking a gingival retraction cord before placement, or rubbing the hemostatic agent against the tissues before retraction cord application, contamination of the prepared cavity to be restored is unavoidable. Previous studies investigated the effect of this contamination on dentin as well as the bond strength to resin composite and resin cements showing that both $\mathrm{AlCl}_{3}$ and $\mathrm{Fe}_{2}\left(\mathrm{SO}_{4}\right)_{3}$ resulted in a disturbance of the dentinal smear layer ${ }^{6,7}$, demineralization of dentin ${ }^{8}$, and reduction in bond strength of resin composite and self-adhesive resin cements ${ }^{8-12)}$.
Resin-modified glass ionomer cement (RMGIC) is a restorative materials having less sensitivity to water balance and superior physical properties compared to conventional glass ionomer cements ${ }^{13,14)}$, with a fluoride releasing property ${ }^{15}$, chemical bond to dental tissue and adhesion in wet field ${ }^{16}$. This makes it a restorative choice for deep subgingival lesions, including the open and closed sandwich techniques ${ }^{17,18)}$ and as a core material ${ }^{19)}$. In these situations, contamination of the prepared cavity in root dentin with a hemostatic agent is more likely to happen.

RMGIC incorporates both chemical adhesion to the tooth structure by ionic interaction between the calcium in hydroxyapatite (HAp) of tooth structure and carboxyl groups of the RMGIC, in addition to a resin based micromechanichal interlocking ${ }^{20}$. Previous studies reported that using a conditioning agent is mandatory to enhance the bond of the RMGIC to prepared dentin ${ }^{21,22)}$, some other studies reported that dentin treatment with a self-etch adhesive system (SEA) containing primer and bonding agent was able to significantly enhance the bond of RMGIC ${ }^{16,23,24)}$, the role of the primer is to simultaneously etch and prime tooth substrate, enhancing the monomer penetration into the hydrophilic dentin and improving its wettability ${ }^{25,26)}$, and this may enhance the resin bonding mechanism of RMGIC to dentin. There is currently no information testing whether the use of a self-etch primer without bonding agent prior to RMGIC placement will provide good adhesion compared with that achieved by dentin conditioners. In addition, it still remains unclear if hemostatic agents will affect the 
bond strength of RMGIC to dentin. Therefore, the aim of this study was to evaluate the effect of two hemostatic agents containing $\mathrm{AlCl}_{3}$ or $\mathrm{Fe}_{2}\left(\mathrm{SO}_{4}\right)_{3}$ on bond strength of RMGIC to root dentin after using different conditioning solutions that includes the use of a self-etching primer from an enamel-dentin adhesive system.

\section{MATERIALS AND METHODS}

Materials used in this study

Two restorative materials were used; RMGIC (Fuji II LC capsule, GC, Tokyo, Japan), and resin composite (Clearfil APX, Kuraray Noritake Dental, Tokyo, Japan) shade A2, two hemostatic agents; Viscostat Clear (Ultradent Products, South Jordan UT, USA), an $\mathrm{AlCl}_{3}$ hemostatic agent, and Viscostat (Ultradent Products), a $\mathrm{Fe}_{2}\left(\mathrm{SO}_{4}\right)_{3}$ hemostatic agent, the conditioning solutions were; Cavity Conditioner (GC), Self Conditioner (GC), Clearfil SE primer (Kuraray Noritake Dental), or twostep self-etch adhesive Clearfil SE Bond (Kuraray Noritake Dental), their compositions and methods of application are presented in Table 1. Sixty extracted bovine teeth were collected, pulp tissues removed and the root surfaces cleaned using periodontal curettes, then a low-speed diamond saw (Isomet, Buehler, Lake Bluff, IL, USA) was used to separate the crown and the

Table 1 Restorative and conditioning materials used, manufacturer, batch no., composition and method of application

\begin{tabular}{cccc}
\hline Material & $\begin{array}{c}\text { Brand name and } \\
\text { manufacturer }\end{array}$ & Code & Chemical composition
\end{tabular}

\begin{tabular}{|c|c|c|c|c|}
\hline \multirow{2}{*}{$\begin{array}{l}\text { Hemostatic } \\
\text { agents }\end{array}$} & $\begin{array}{l}\text { Viscostat Clear } \\
\text { (Ultradent Products, } \\
\text { South Jordan, UT, } \\
\text { USA) (B\#: BD6BT). }\end{array}$ & VSC & $25 \%$ aluminum chloride & $\begin{array}{l}\text { The gel applied on dentin surface } \\
\text { for } 5 \text { min and rinsed with water } \\
\text { for } 20 \mathrm{~s} \text {. }\end{array}$ \\
\hline & $\begin{array}{l}\text { Viscostat (Ultradent } \\
\text { Product) (B\#: BDB4S). }\end{array}$ & VS & $20 \%$ ferric sulfate & $\begin{array}{l}\text { The gel applied on dentin surface } \\
\text { for } 5 \text { min and rinsed with water } \\
\text { for } 20 \mathrm{~s} \text {. }\end{array}$ \\
\hline \multirow{3}{*}{$\begin{array}{l}\text { Conditioning } \\
\text { agents }\end{array}$} & $\begin{array}{l}\text { Cavity Conditioner } \\
\text { (GC, Tokyo, Japan) } \\
\text { (B\#:1508101). }\end{array}$ & $\mathrm{CC}$ & $\begin{array}{l}77 \% \text { distilled water, } 20 \% \\
\text { polyacrylic acid, } 3 \% \text { aluminum } \\
\text { chloride hydrate }\end{array}$ & $\begin{array}{l}\text { Applied to cavity surface for } 10 \mathrm{~s} \text {. } \\
\text { Rinsed thoroughly with water and } \\
\text { dried without desiccation. }\end{array}$ \\
\hline & 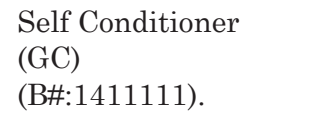 & $\mathrm{SC}$ & $\begin{array}{l}20-30 \% \text { HEMA, } 5-10 \% \\
\text { 4-META, 30-35\% distilled water, } \\
28-40 \% \text { ethanol }\end{array}$ & $\begin{array}{l}\text { Applied to cavity surface and left } \\
\text { undisturbed for } 10 \mathrm{~s} \text {. } \\
\text { Air dried for } 5 \mathrm{~s} \text {. }\end{array}$ \\
\hline & $\begin{array}{l}\text { Clearfil SE primer } \\
\text { (Kuraray Noritake } \\
\text { Dental, Tokyo, Japan) } \\
\text { (B\#: 9H0109). }\end{array}$ & SEP & $\begin{array}{l}\text { MDP, HEMA, hydrophilic } \\
\text { aliphatic dimethacrylate, } \\
\text { di-Camphorquinone, } \\
\text { N-diethanol-p-toluidine, water }\end{array}$ & $\begin{array}{l}\text { Primer applied to cavity surface } \\
\text { with continuous rubbing for } 20 \mathrm{~s} \text {, } \\
\text { Air dried for } 5 \mathrm{~s} \text {. }\end{array}$ \\
\hline
\end{tabular}

$\begin{array}{lll} & & \begin{array}{l}\text { Primer: MDP, HEMA, hydrophilic } \\ \text { aliphatic dimethacrylate, } \\ \text { di-Camphorquinone, }\end{array} \\ \text { Self-etch } & \text { Clearfil SE Bond } & \text { N-diethanol-p-toluidine, water } \\ \text { adhesive } & \text { (Kuraray Noritake } & \text { (B\#: } 9 \text { H0109) } \\ \text { system } & \text { Dental) } & \text { Adhesive: MDP, Bis-GMA, HEMA, } \\ & \text { hydrophilic dimethacrylate, and } \\ & \text { microfiller (B\#: 1R0296) } \\ & \\ & \end{array}$

\begin{tabular}{|c|c|c|c|c|}
\hline \multirow{2}{*}{$\begin{array}{l}\text { Restorative } \\
\text { materials }\end{array}$} & $\begin{array}{l}\text { Fuji II LC capsule } \\
\text { shade A2. (GC) } \\
\text { (B\#: 1610137) }\end{array}$ & - & $\begin{array}{l}\text { Fluoro-alumino-silicate glass, } \\
\text { Polyacrylic acid, HEMA, } \\
\text { urethane dimethacrylate, } \\
\text { camphorquinone, water }\end{array}$ & $\begin{array}{l}\text { Capsule mixed for } 10 \mathrm{~s} \text { and } \\
\text { applied on dentin surface, } \\
\text { then Light cured for } 20 \mathrm{~s} \text {. }\end{array}$ \\
\hline & $\begin{array}{l}\text { Clearfil AP-X } \\
\text { shade A3 (Kuraray } \\
\text { Noritake Dental), } \\
\text { Japan) (B\#: 440059) }\end{array}$ & - & $\begin{array}{l}\text { Bis-GMA, TEGDMA, } \\
\left.\text { filler (Barium, } \mathrm{SiO}_{2}\right) \text {, } \\
\text { dl Camphorquinone } \\
\text { Catalysts Accelerators }\end{array}$ & $\begin{array}{l}\text { Applied as one increment not } \\
\text { exceeding } 2 \mathrm{~mm} \text { in thickness and } \\
\text { light cured for } 40 \mathrm{~s} \text {. }\end{array}$ \\
\hline
\end{tabular}

Bis-GMA: bisphenol-A-diglycidylmethacrylate, HEMA: 2-hydroxyethylmethacrylate, MDP: 10-methacryloyloxydecyl dihydrogen phosphate, 4-META: 4-methacryloxyethyl trimellitate anhydride, TEGDMA: triethyleneglycol dimethacrylate
Primer applied to cavity surface with continuous rubbing for $20 \mathrm{~s}$ then air dried for $5 \mathrm{~s}$.

Bond applied to surface, spread uniformly with light air stream, and light cured for $10 \mathrm{~s}$.

Capsule mixed for $10 \mathrm{~s}$ and applied on dentin surface, then Light cured for $20 \mathrm{~s}$.

Applied as one increment not exceeding $2 \mathrm{~mm}$ in thickness and light cured for $40 \mathrm{~s}$. 
apical two-thirds of the root under water cooling, the remaining central/cervical root portion was sectioned along the root long axis and transversally to obtain two dentin blocks from cervical part of the root just apical to the cemento-enamel junction. Each root dentin block was embedded in epoxy resin (Epoxicure 2, Buehler) using a cylindrical mold. After setting of the resin the root surface was ground manually with \#600-grit SiC paper under running water to expose a flat standardized dentin surface.

\section{Specimen preparation}

The specimens were divided according to the dentin surface treatment with hemostatic agents into untreated (control) or treated (contaminated) with one of two hemostatic agents, Viscostat Clear (VSC) or Viscostat (VS). their application time was five minutes $\mathrm{s}^{6,7,10)}$ followed by rinsing off with a vigorous water spray for $20 \mathrm{~s}$, after this, for the RMGIC groups the surface was treated with either Cavity Conditioner (CC), Self Conditioner (SC), or Clearfil SE Primer (SEP), according to the manufacturer's instructions (Table 1). Fuji II LC capsule was mixed using a GC Capsule Mixer (CM-II, GC) for $10 \mathrm{~s}$, applied on the dentin surface in a cylindrical mold of $2 \mathrm{~mm}$ thickness and light cured for $20 \mathrm{~s}$ using a quartz halogen light curing unit (Optilux 501, Kerr, Danbury, CT, USA) at $600 \mathrm{~mW} / \mathrm{cm}^{2}$.

For the resin composite groups, Clearfil SE Bond was applied according to the manufacturer's instructions (Table 1) on dentin contaminated with one of the hemostatic agents or on non-contaminated surface used as control (CR/control). Then the resin composite Clearfil APX was placed using the same cylindrical mold and light cured for $40 \mathrm{~s}$. All the specimens were stored separately in distilled water at $37^{\circ} \mathrm{C}$ for $24 \mathrm{~h}$.

\section{Microtensile bond strength ( $\mu$ TBS) test}

After storage, each bonded specimen was sectioned longitudinally both buccal-lingually and mesiodistally across the bonded interface to obtain multiple sticks of approximately $1 \mathrm{~mm}^{2}$ for the $\mu$ TBS test. A total of 40 sticks obtained from five different teeth for each subgroup were tested. A digital caliper (Mitutoyo, Kawasaki, Japan) was used to check the cross-sectional area of each stick, which was then fixed to the test apparatus with a cyanoacrylate adhesive (Zapit, Dental Ventures of American, Anaheim Hills, CA, USA) and stressed in tension on a universal testing machine (EZTest, Shimadzu, Kyoto, Japan) at a crosshead speed of $1 \mathrm{~mm} / \mathrm{min}$ until failure. The procedures of specimen preparation for the $\mu$ TBS test are shown briefly in Fig. 1.

\section{Failure mode analysis}

After debonding, specimens were fixed on a specimen holder with double-sided adhesive tape and sputtercoated for evaluation under SEM (S-4500, Hitachi, Tokyo, Japan) at $15 \mathrm{kV}$ accelerating voltage. Failure modes were classified into the following categories; adhesive failure (A) (failure at the dentin-material interface), cohesive failure in restorative material (C), cohesive failure in dentin (D), and mixed failure (M), (partially adhesive and cohesive failure).

SEM observations of the contaminated dentin surfaces To evaluate the effect of contamination with the hemostatic agents, dentin surfaces with/without hemostatic agent application were prepared. The specimens were then desiccated for $24 \mathrm{~h}$, and gold sputter-coated for SEM observation (S-4500, Hitachi).

\section{Statistical analysis}

Normal distribution of data was assumed after Kolmogorov-Smirnov and Shapiro-Wilk tests. Two-way analysis of variance (ANOVA) was used to compare between different tested conditioning Materials and hemostatic Agent on mean $\mu \mathrm{TBS}(\mathrm{MPa})$ followed by pairwise comparisons with Bonferroni correction. (SPSS V.23, SPSS, Chicago, IL, USA).

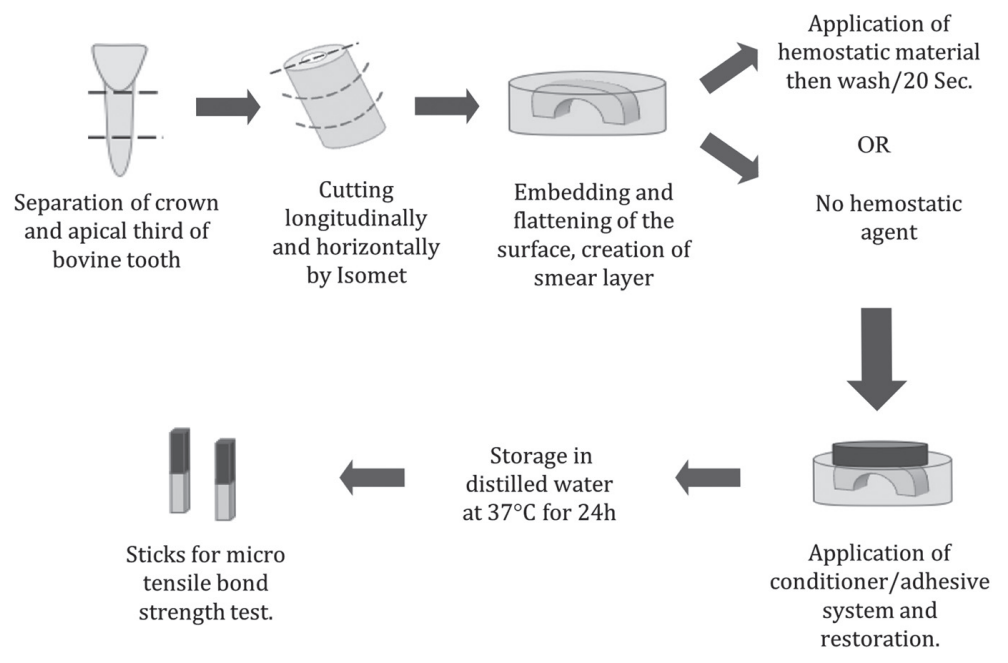

Fig. 1 Schematic showing specimen preparation for the $\mu$ TBS test. 


\section{RESULTS}

Table 2 shows the mean $\mu$ TBS values of the RMGIC and resin composite to dentin contaminated with the hemostatic agents.

Two-way ANOVA showed that conditioning materials had a highly significant effect on mean $\mu$ TBS at $p \leq 0.001$, while the hemostatic agents showed nonsignificant effect on mean $\mu \mathrm{TBS}$ at $p>0.05$. Among RMGIC groups, SEP showed the highest bond strength values, followed by SC, then $\mathrm{CC}$ which showed the lowest $\mu$ TBS values for all conditioning agents with significant differences between each of them at $p \leq 0.001$.

Contamination with VSC or VS caused no significant change $(p>0.05)$ in bond strength among all RMGIC groups. For the resin composite groups, VSC caused no significant reduction in $\mu \mathrm{TBS}$, while VS contamination led to a significant reduction $(p \leq 0.001)$. The $\mu$ TBS values of all the RMGIC groups were significantly lower than the resin composite groups.

Regarding the results of the failure mode analysis (Table 3), the mixed mode of failure (M) predominated for all groups, except for CC/VS, which was adhesive

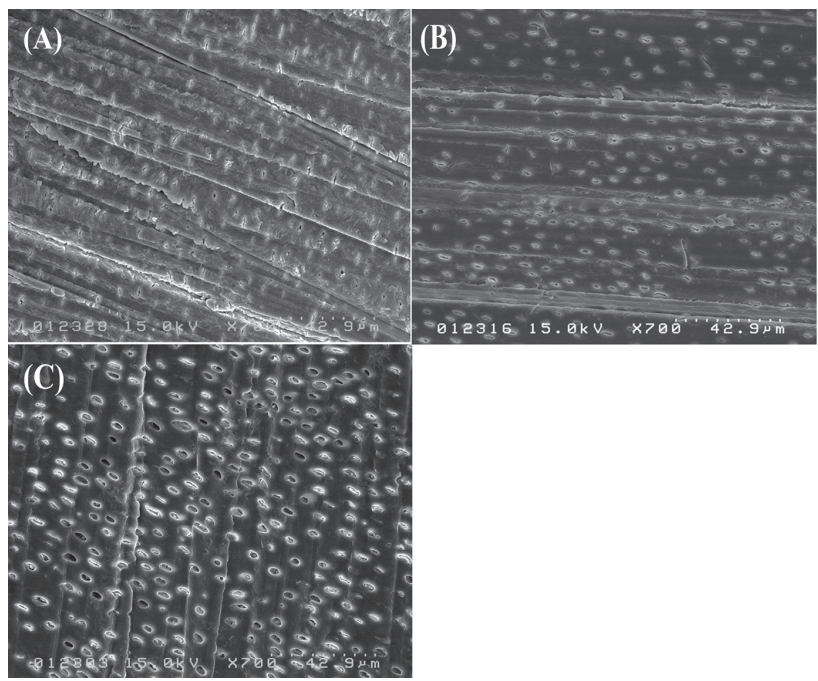

Fig. 2 SEM images of dentin surfaces after finishing with 600-grit $\mathrm{SiC}$ paper and (A) rinsing with water for $20 \mathrm{~s}$, (B) application of Viscostat Clear for $5 \mathrm{~min}$ and rinsing with water for $20 \mathrm{~s}$, (C) application of Viscostat for 5 min and rinsing with water for $20 \mathrm{~s}$.

Table 2 Mean values and (SD) of $\mu$ TBS (MPa) of the tested groups

\begin{tabular}{lllll}
\hline & & Control & VSC & VS \\
\hline \multirow{2}{*}{ RMGIC Fuji II LC } & CC & $17.1(2.3)^{\mathrm{a}}$ & $17.7(2.8)^{\mathrm{a}}$ & $16.1(2.8)^{\mathrm{a}}$ \\
& SC & $26.0(4.6)^{\mathrm{b}}$ & $24.6(3.6)^{\mathrm{b}}$ & $23.4(3.2)^{\mathrm{b}}$ \\
AP-X composite resin & SEP & $33.8(5.8)^{\mathrm{c}}$ & $30.8(4.8)^{\mathrm{c}}$ & $28.9(4.3)^{\mathrm{c}}$ \\
\hline
\end{tabular}

Groups identified by similar small letters were not significantly different at $p>0.05$.

CC: Cavity Conditioner, SC: Self Conditioner, SEP: Clearfil SE primer, VSC: Viscostat clear, VS: Viscostat

Table 3 Failure mode (in percent) of the debonded specimens of different experimental groups

\begin{tabular}{|c|c|c|c|c|c|c|}
\hline Material & Conditioning & Hemostatic agent & $\mathrm{A}$ & M & $\mathrm{C}$ & $\mathrm{D}$ \\
\hline \multirow{9}{*}{ RMGIC Fuji II LC } & \multirow{3}{*}{$\mathrm{CC}$} & control & 35 & 40 & 25 & 0 \\
\hline & & VSC & 38 & 38 & 24 & 0 \\
\hline & & VS & 38 & 35 & 27 & 0 \\
\hline & \multirow{3}{*}{$\mathrm{SC}$} & control & 17 & 45 & 33 & 5 \\
\hline & & VSC & 25 & 45 & 30 & 0 \\
\hline & & VS & 30 & 43 & 27 & 0 \\
\hline & \multirow{3}{*}{ SEP } & control & 10 & 35 & 45 & 10 \\
\hline & & VSC & 9 & 40 & 39 & 12 \\
\hline & & VS & 14 & 43 & 38 & 5 \\
\hline \multirow{3}{*}{ AP-X composite resin } & \multirow{3}{*}{ SE Bond } & control & 20 & 63 & 8 & 9 \\
\hline & & VSC & 18 & 63 & 9 & 10 \\
\hline & & VS & 24 & 65 & 5 & 6 \\
\hline
\end{tabular}

A: adhesive failure, M: mixed failure, C: cohesive failure in restoration, D: cohesive failure in dentin 
failure (A) and the SEP/control group which exhibited predominantly cohesive failure in restoration. It was noted also that the adhesive failure rate increased slightly among the Viscostat contaminated groups.

The morphological characteristics of the dentin surfaces after hemostatic agent contamination are shown in Fig. 2. In the control group (no treatment) the smear layer remained intact and thick, and dentin tubules could not be clearly identified (Fig. 2A). The hemostatic agent contaminated specimens showed noticeable etching effects of the dentin. For the $\mathrm{AlCl}_{3}$ application group (Fig. 2B), most of the smear layer was removed exposing dentinal tubules, however, they remained occluded in most cases. For the $\mathrm{Fe}_{2}\left(\mathrm{SO}_{4}\right)_{3}$ group (Fig. $2 \mathrm{C}$ ) the etching effect was more pronounced with the dentinal tubules remaining partially occluded.

\section{DISCUSSION}

$\mathrm{AlCl}_{3}$ and $\mathrm{Fe}_{2}\left(\mathrm{SO}_{4}\right)_{3}$ containing hemostatic agents are among the most common topical hemostats in restorative dentistry. Current agents were in a gel form, which has a lower potential to spread over dentin surface than liquid ones, however, their viscous nature makes it harder to be removed from a dentin surface ${ }^{12)}$. The 5-min exposure time of the hemostatic agent was chosen, as long exposure times are not unusual especially with complex restorative procedures when there are multiple tooth preparations $s^{7}$.

The 2-step self-etch adhesive system and resin composite showed reduced $\mu$ TBS values to dentin for both of the hemostatic agents. This result is consistent with those of the previous studies ${ }^{9,12,27)}$, although the application time of the hemostatic material was different in each study. It was shown previously ${ }^{6,7)}$ that the acidic $\mathrm{pH}$ of the tested astringents resulted in smear layer removal, and dentin etching effects, hence confirmatory SEM radiographs of dentin surface treated with the current hemostatic agents were obtained. For the $\mathrm{Fe}_{2}\left(\mathrm{SO}_{4}\right)_{3}$, it is postulated that the changes to the dentin surface were responsible for this reduction. Previous studies showed that $5 \mathrm{~min}$ application of $\mathrm{Fe}_{2}\left(\mathrm{SO}_{4}\right)_{3}$ resulted in severe etching ${ }^{6,7,10)}$, which is consistent with the SEM micrographs from the current study, however, the dentinal tubules remained partly occluded. It was postulated that collagen or plasma proteins could have been coagulated by the $\mathrm{Fe}_{2}\left(\mathrm{SO}_{4}\right)_{3}{ }^{12)}$ that were unable to be cleansed or removed totally by the self-etch primer, thus, affecting the bond strength. For the $\mathrm{AlCl}_{3}$ containing hemostatic agent, the reduction (which was non-significant) may be attributed to the higher $\mathrm{Al}$ content remaining on the contaminated dentin surface even after application of self-etch primer -as previously proven by energy dispersive spectrometer (EDS) analysis ${ }^{8,28)}$ - resulting in displacement of calcium in the $\mathrm{HAp}$ by $\mathrm{Al}$, forming an insoluble $\mathrm{Al}(\mathrm{OH})_{2} \mathrm{H}_{2} \mathrm{PO}_{4}$ compound which cannot be easily removed by the selfetching monomer, however, a previous study ${ }^{8}$ ) showed that this reduction was significant. Regarding the effect of the $\mathrm{AlCl}_{3}$ on the dentin surface, it caused noticeable dentin etching but not severe as the $\mathrm{Fe}_{2}\left(\mathrm{SO}_{4}\right)_{3}{ }^{7}$.

Cavity Conditioner is recommended by the manufacturer as the conditioning agent for Fuji II LC. It is composed of $20 \%$ polyacrylic acid and $3 \%$ aluminum chloride hydrate, its mode of action includes (1) cleaning the surface by removal of the smear layer (2) and a partial demineralization effect which increases the surface area for bonding by creating micro-porosities for micro-mechanical interlocking and formation of shallow hybrid layers that also contribute to the micromechanical bonding ${ }^{29,30)}$.

The bond strength of RMGIC can be enhanced by improving the resin bonding mechanism because of its resin component, as well as the quality of the hybrid layer. Self Conditioner was reported to increase the bond strength of RMGIC ${ }^{21,22)}$, it contains both 4-META, a functional monomer that chemically interacts with the HAp in dentin ${ }^{31,32)}$, and HEMA, which improves the dentin wettability and RMGIC spread and penetration into the dentin ${ }^{26}$. When combined, these factors can improve the quality of the hybrid layer ${ }^{33)}$ which may be the major source of the enhanced bond strength ${ }^{22)}$. Using SE primer only as pretreatment agent eliminates the need of bonding agent application or light curing, which is easier and more time saving compared to SEA. SE primer may have improved the bond strength in a similar fashion as SC, as both have a similar $\mathrm{pH}$ (SE primer 2.0 and SC 1.8). But the superior bond strength values with SE primer may be attributed to its MDP content as a functional monomer or its longer application time when the manufacturer recommendation was followed.

Dentin contamination with either of hemostatic agents used in this study did not significantly affect the bond strengths of the RMGIC groups, especially when Cavity Conditioner was used. The bonding of RMGIC to tooth structure is achieved via primary chemical bonding occurring through the formation of ionic bonds between the carboxyl groups of the polyalkenoic acid and calcium of HAp that remained around the exposed surface collagen, and micromechanical interlocking, achieved by infiltration of the organic tags of RMGIC components into a partially de-mineralized dentin surface ${ }^{24)}$. This two-fold bonding mechanism was not significantly affected after using the hemostatic agents. It has been previously reported that phosphoric acid etching improved the effect of self-etch adhesive in enhancing the bond strength of RMGIC ${ }^{22}$. Therefore, the etching effect of the hemostatic agents may have influenced the RMGIC bonding in the SC and SEP groups favorably. However, further investigation is required to better understand the exact reason for these results.

It should be mentioned that many previous experiments have used resin composite, unlike conventional glass ionomer cement, therefore it was preferred to be the positive control restorative material, because an expected result can be presumed from previous literature. In addition, a sort of similarity between the contamination effect of viscostat/viscostat clear and other $\mathrm{Fe}_{2}\left(\mathrm{SO}_{4}\right)_{3} / \mathrm{AlCl}_{3}$ astringents can be confirmed with the composite resin groups. The resin content in Fuji II 


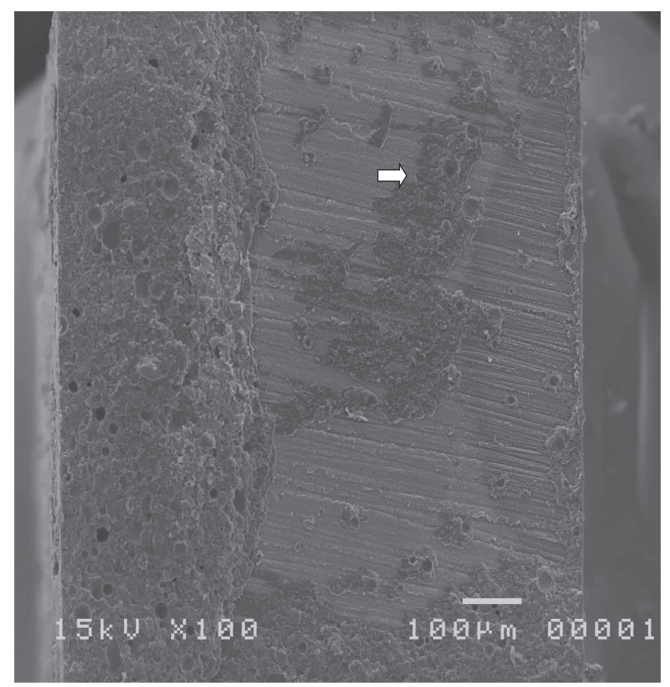

Fig. 3 SEM image showing a mixed failure in SEP/Control specimen along the dentin side, the white arrow points to thin RMGIC area indicating fracture occurring at the base of the restorative material.

LC as well as with using SE primer in this experiment was another reason to select the current positive control groups. Similar future studies using conventional glass ionomers are recommended.

Failure mode analysis in the resin composite groups was predominantly mixed, with higher frequency of adhesive failure in the CR/VS group. With the RMGIC groups the predominant mode of failure was mixed with CC and SC, and cohesive with SEP with a frequent incidence of dentin cohesive fractures. It was also noticed that with in SEP and SC groups, there was high incidence of fractures at the base of the RMGIC, leaving thin resin surface covering the dentin (white arrow in Fig. 3), suggesting improved RMGIC penetration into dentinal tubules as well as an improvement of the hybrid layer at the RMGIC-dentin interface. It should be noted that bond strength values of all resin composite groups were higher than those of RMGIC groups, which had a higher cohesive and mixed failure in the restorative material. This would seem to indicate that the inherent strength of the material remains an obstacle in achieving bond strength values close to that of resin composite restorations.

\section{CONCLUSION}

Based on the results of this study, neither the $\mathrm{AlCl}_{3}$ or $\mathrm{Fe}_{2}\left(\mathrm{SO}_{4}\right)_{3}$ hemostatic agents significantly affected the bond strength of RMGIC to dentin, in addition, using a self-etching primer significantly increased the bond strength of RMGIC compared to either Cavity Conditioner and Self Conditioner.

\section{REFERENCES}

1) Yoo HM, Pereira PN. Effect of blood contamination with 1-step self-etching adhesives on microtensile bond strength to dentin. Oper Dent 2006; 31: 660-665.

2) Kimmes NS, Olson TL, Shaddy RS, Latta MA. Effect of ViscoStat and ViscoStat plus on composite shear bond strength in the presence and absence of blood. J Adhes Dent 2006; 8: 363-366.

3) Khoroushi M, Tavasoli M. The effect of trichloracetic acid as a hemostatic and etching agent on the morphological characteristics and shear bond strength of resin composite to enamel. Oper Dent 2010; 35: 187-193.

4) Burrel KH, Glick M. Hemostatics, astringents and gingival retraction cords. Ciancio SG, ed, ADA Guide to Dental Therapeutics 2nd ed, Chicago, American Dental Association 2000: 104-118.

5) Smith NL, Seale NS, Nunn ME. Ferric sulfate pulpotomy in primary molars: A retrospective study. Pediatr Dent 2000; 22: 192-199.

6) Land MF, Rosenstiel SF, Sandrik JL. Disturbance of the dentinal smear layer by acidic hemostatic agents. J Prosthet Dent 1994; 72: 4-7.

7) Land MF, Couri CC, Johnston WM. Smear layer instability caused by hemostatic agents. J Prosthet Dent 1996; 76: 477 482.

8) Kuphasuk W, Harnirattisai C, Senawongse P, Tagami J. Bond strengths of two adhesive systems to dentin contaminated with a hemostatic agent. Oper Dent 2007; 32: 399-405.

9) Khoroushi M, Hosseini-Shirazi M, Farahbod F, Keshani F. Composite resin bond strength to caries-affected dentin contaminated with 3 different hemostatic agents. Gen Dent 2016; 64: e11-15.

10) Chaiyabutr Y, Kois JC. The effect of tooth-preparation cleansing protocol on the bond strength of self-adhesive resin cement to dentin contaminated with a hemostatic agent. Oper Dent 2011; 36: 18-26.

11) Bernades Kde O, Hilgert LA, Ribeiro AP, Garcia FC, Pereira $\mathrm{PN}$. The influence of hemostatic agents on dentin and enamel surfaces and dental bonding: A systematic review. J Am Dent Assoc 2014; 145: 1120-1128.

12) O'Keefe KL, Pinzon LM, Rivera B, Powers JM. Bond strength of composite to astringent-contaminated dentin using selfetching adhesives. Am J Dent 2005; 18: 168-172.

13) Small IC, Watson TF, Chadwick AV, Sidhu SK. Water sorption in resin-modified glass-ionomer cements: An in vitro comparison with other materials. Biomaterials 1998; 19: 545550.

14) Tyas MJ, Burrow MF. Adhesive restorative materials: A review. Aust Dent J 2004; 49: 112, 21; quiz 154

15) Takahashi K, Emilson CG, Birkhed D. Fluoride release in vitro from various glass ionomer cements and resin composites after exposure to NaF solutions. Dent Mater 1993; 9: 350-354.

16) Dursun E, Attal JP. Combination of a self-etching adhesive and a resin-modified glass ionomer: Effect of water and saliva contamination on bond strength to dentin. J Adhes Dent 2011; 13: 439-443.

17) Kasraei S, Azarsina M, Majidi S. In vitro comparison of microleakage of posterior resin composites with and without liner using two-step etch-and-rinse and self-etch dentin adhesive systems. Oper Dent 2011; 36: 213-221.

18) Loguercio AD, Alessandra R, Mazzocco KC, Dias AL, Busato AL, Singer Jda M, Rosa P. Microleakage in class II composite resin restorations: Total bonding and open sandwich technique. J Adhes Dent 2002; 4: 137-144.

19) Bonilla ED, Mardirossian G, Caputo AA. Fracture toughness of various core build-up materials. J Prosthodont 2000; 9: 1418. 
20) Tanumiharja M, Burrow MF, Tyas MJ. Microtensile bond strengths of glass ionomer (polyalkenoate) cements to dentine using four conditioners. J Dent 2000; 28: 361-366.

21) Saad A, Inoue G, Nikaido T, Ikeda M, Burrow MF, Tagami J. Microtensile bond strength of resin-modified glass ionomer cement to sound and artificial caries-affected root dentin with different conditioning. Oper Dent 2017; 42: 626-635.

22) Imbery TA, Namboodiri A, Duncan A, Amos R, Best AM, Moon PC. Evaluating dentin surface treatments for resin-modified glass ionomer restorative materials. Oper Dent 2013; 38: 429438.

23) Besnault C, Attal JP, Ruse D, Degrange M. Self-etching adhesives improve the shear bond strength of a resin-modified glass-ionomer cement to dentin. J Adhes Dent 2004; 6: 5559.

24) Poggio C, Beltrami R, Scribante A, Colombo M, Lombardini M. Effects of dentin surface treatments on shear bond strength of glass-ionomer cements. Ann Stomatol (Roma) 2014; 5: 1522.

25) Erickson RL. Surface interactions of dentin adhesive materials. Oper Dent 1992; Suppl 5: 81-94.

26) Giannini M, Makishi P, Ayres AP, Vermelho PM, Fronza BM, Nikaido T, Tagami J. Self-etch adhesive systems: A literature review. Braz Dent J 2015; 26: 3-10.

27) Ebrahimi SF, Shadman N, Abrishami A. Effect of ferric sulfate contamination on the bonding effectiveness of etchand-rinse and self-etch adhesives to superficial dentin. J Conserv Dent 2013; 16: 126-130.

28) Harnirattisai C, Kuphasuk W, Senawongse P, Tagami J. Bond strengths of resin cements to astringent-contaminated dentin. Oper Dent 2009; 34: 415-422.

29) Coutinho E, Yoshida Y, Inoue S, Fukuda R, Snauwaert J, Nakayama Y, De Munck J, Lambrechts P, Suzuki K, Van Meerbeek B. Gel phase formation at resin-modified glassionomer/tooth interfaces. J Dent Res 2007; 86: 656-661.

30) Abdalla AI. Morphological interface between hybrid ionomers and dentin with and without smear-layer removal. J Oral Rehabil 2000; 27: 808-814.

31) Shinagawa J, Inoue G, Nikaido T, Ikeda M, Sadr A, Tagami J. Dentin bonding performance and interface observation of an MMA-based restorative material. Dent Mater J 2016; 35: 578-584.

32) Yoshida Y, Nagakane K, Fukuda R, Nakayama Y, Okazaki M, Shintani H, Inoue S, Tagawa Y, Suzuki K, De Munck J, Van Meerbeek B. Comparative study on adhesive performance of functional monomers. J Dent Res 2004; 83: 454-458.

33) Coutinho E, Van Landuyt K, De Munck J, Poitevin A, Yoshida Y, Inoue S, Peumans M, Suzuki K, Lambrechts P, Van Meerbeek B. Development of a self-etch adhesive for resin-modified glass ionomers. J Dent Res 2006; 85: 349-353. 